\title{
Role of Muc1, Muc2, Muc4 And Cyclin D1 in The Evaluation And Prognostication of Biliary Tract Malignancy
}

\author{
Gupta Lav,Gupta Priyanka, Singhal Sanjeev(HOD) \\ (Department Of Surgery, NRCH,New Delhi, India)
}

\begin{abstract}
.
Introduction: Biliary tract carcinomas are relatively rare, yet the third most common cause of cancer-related death worldwide. Identification of reliable molecular markers may provide valuable prognostic information and facilitate adequate treatment plans and target for a novel therapeutic approach.

Objective:1.to study the distribution of molecular markers among cases and control for predictive value,sensitivity and specificity.2.to study the role of molecular markers in outcome of BTM.

Material and methods:Prospective observational study done in radiologically suspected 70 patients in department of surgerybetween 2013 to 2015.Specimen sent for IHC \& HPE and the result of molecularmarkers are compared among cases and control..Conclusion and

Result:In our study,Muc-1 expression is more specific whereas cyclin D1 expression is more sensitive indicator in differentiating between benign and malignant biliary tract carcinomas, Expression of Mucl and Muc 4 significantly $(p<0.05)$ correlates with high grade of malignancy whereas Muc2 and Cyclin D1 is associated with low grade malignancy but statistically insignificant. $(p>0.05)$. Among these molecular markers expression of Muc-2 significantly affect outcome and its expression is associated with better outcome in patients with Biliary tract malignancy .
\end{abstract}

Keywords: biliary tract malignancy,Cyclin D1,Muc1,Muc2,Muc4

\section{Introduction}

Biliary tract cancers (BTC) comprise a heterogeneous group of neoplasms including gallbladder cancer, intrahepatic cholangiocarcinoma, extrahepaticcholangiocarcinoma and variably, ampullary carcinoma.

Biliary tract carcinomas are relatively rare, representing less than $1 \%$ of cancers [1]. These tumors present a significant therapeutic challenge in that they are often diagnosed at an advanced stage when surgical resection is not feasible and treatment options are limited. Thus, research efforts have concentrated on identifying potential markers of neoplasia that can be incorporated into diagnostic tests and therapeutic modalities for use in individuals at risk for these lethal malignancies.

This review aims to introduce the main features of the important molecular markers of biliary tree tumors. Some considerable tumor markers are Mucin 1, Mucin 2, Mucin 4 and CyclinD1.

\section{Aims And Objectives}

1.To study the distribution of molecular markers among cases and control for predictive value,sensitivity and specificity.

2.To study the role of molecular markers in outcome of BTM\{prognosis of BTM\}

\section{Materials And Method}

A prospective observational study was conducted in Department Of Surgery, NORTHERN RAIlways Central Hospital, New Delhi, from August 2013 to May 2015.In our study we have taken 70 patients who fulfilled the inclusion and exclusion criteria, in all these patients, thorough history was taken and detailed clinical examination was performed, alone with relevant investigations, After preliminary investigation, pre anesthetic checkup, patients were taken up for surgery (whose investigation suggestive of malignancy and are operable) and specimen sent for histopathology and for molecular markers study. Patients whose biopsy are positive for malignancy were taken under case group and those whom investigation were suggestive of malignancies but histopathology negative for malignancy are categorized under control group.

Follow up: All cases were followed up at regular interval of 3 months for first year and 6 monthly there after. At each visit a thorough clinical examination was done to look for features suggestive of metastasis and relevant radiological investigation(USG Abdomen, CECT whole Abdomen) done accordingly whereas controls were followed at 6 monthly interval for first year then annually thereafter. 


\section{Patient Selection-}

\section{- Inclusion criteria:}

1. Patients whose radiological investigations are suspicious of biliary tract malignancies.

- Exclusion criteria:

1. Patient with multiple malignancies.

2. Patients in whom biopsy is not feasible.

\section{Observations}

Table- 1: Distribution of Age Groups (years)

\begin{tabular}{|c|c|c|}
\hline AGE (YEARS) & NO. OF PATIENTS & PERCENTAGE \% \\
\hline $30-40$ & 2 & $2.86 \%$ \\
\hline $40-50$ & 18 & $25.71 \%$ \\
\hline $50-60$ & 36 & $51.43 \%$ \\
\hline $60-70$ & 14 & $20.00 \%$ \\
\hline TOTAL & 70 & $100 \%$ \\
\hline
\end{tabular}

Table-2: Sex variation

\begin{tabular}{|c|c|c|}
\hline SEX & $\mathrm{N}$ & $\%$ \\
\hline Male & 24 & $34.29 \%$ \\
\hline Female & 46 & $65.71 \%$ \\
\hline TOTAL & 70 & $100 \%$ \\
\hline
\end{tabular}

Out of 70 patients, maximum no. of patients are female with $65.71 \%$ having an approximate ratioof male:female of 1:2.

Table -3: Histological Vs radiological Diagnosis

\begin{tabular}{|l|c|c|}
\hline \multicolumn{1}{|c|}{ Histopathology } & $\mathrm{N}$ & $\%$ \\
\hline Positive & 30 & $42.86 \%$ \\
\hline Negative & 40 & $57.14 \%$ \\
\hline TOTAL & 70 & $100 \%$ \\
\hline
\end{tabular}

Since all patients were suspicious of malignancy on radiological background but true positive (biopsy proven malignant) were only $42.86 \%$.

Table 4: Grade of Malignancy Among Histologially Positive Patients:

\begin{tabular}{|l|c|c|}
\hline HPE GRADE & $\mathrm{N}$ & $\%$ \\
\hline High & 18 & $60.00 \%$ \\
\hline Low & 12 & $40.00 \%$ \\
\hline TOTAL & 30 & $100 \%$ \\
\hline
\end{tabular}

Table 5: Distribution of molecular markers among cases and controls with their sensitivity, specificity and predictive values:

\begin{tabular}{|c|c|c|c|c|c|c|c|c|c|c|}
\hline \multirow{2}{*}{$\begin{array}{l}\text { Histopathology } \\
\rightarrow\end{array}$} & \multicolumn{2}{|c|}{ Positive } & \multicolumn{2}{|c|}{ Negative } & \multirow{2}{*}{$\begin{array}{c}\mathrm{p}- \\
\text { value }\end{array}$} & \multirow[t]{2}{*}{ Sensitivity } & \multirow[t]{2}{*}{ Specificity } & \multirow[t]{2}{*}{ PPV } & \multirow[t]{2}{*}{ NPV } & \multirow{2}{*}{$\begin{array}{l}\text { Diagnostic } \\
\text { accuracy }\end{array}$} \\
\hline & $\mathrm{n}$ & $\%$ & $\mathrm{n}$ & $\%$ & & & & & & \\
\hline Mucin 1 & 16 & $53.33 \%$ & 10 & $25.00 \%$ & 0.043 & $53.33 \%$ & $75.00 \%$ & $61.54 \%$ & $68.18 \%$ & $65.71 \%$ \\
\hline Mucin 2 & 6 & $20.00 \%$ & 4 & $10.00 \%$ & 0.201 & $20.00 \%$ & $90.00 \%$ & $60.00 \%$ & $60.00 \%$ & $60.00 \%$ \\
\hline Mucin 4 & 16 & $53.33 \%$ & 12 & $30.00 \%$ & 0.082 & $53.33 \%$ & $70.00 \%$ & $57.14 \%$ & $66.67 \%$ & $62.86 \%$ \\
\hline Cyclin D1 & 22 & $73.33 \%$ & 12 & $30.00 \%$ & 0.006 & $73.33 \%$ & $70.00 \%$ & $64.71 \%$ & $77.78 \%$ & $71.43 \%$ \\
\hline
\end{tabular}

Table-6:Distribution of molecular markers in relation to grade of malignancy:

\begin{tabular}{|l|c|c|c|c|c|}
\hline \multirow{2}{*}{ HPE Grade $\rightarrow$} & High & \multicolumn{2}{|c|}{ Low } & \multirow{2}{*}{ p-value } \\
\cline { 2 - 5 } & $\mathrm{n}$ & $\%$ & $\mathrm{n}$ & $\%$ & 0.259 \\
\hline Mucin 1 & 12 & $66.67 \%$ & 6 & $50.00 \%$ & 0.146 \\
\hline Mucin 2 & 2 & $11.11 \%$ & 4 & $33.33 \%$ & 0.005 \\
\hline Mucin 4 & 6 & $100.00 \%$ & 12 & $33.33 \%$ & 0.057 \\
\hline Cyclin D1 & 12 & $66.67 \%$ & 12 & $100.00 \%$ & \\
\hline
\end{tabular}

Table-7: Outcome of patients Vs molecular markers:

\begin{tabular}{|l|c|c|c|c|c|}
\hline \multirow{2}{*}{ Outcome $\rightarrow$} & \multicolumn{2}{|c|}{ Expired } & \multicolumn{2}{c|}{ Alive } & \multirow{2}{*}{ p-value } \\
\cline { 2 - 5 } & $\mathrm{n}$ & $\%$ & $\mathrm{n}$ & $\%$ & \\
\hline Mucin 1 & 6 & $37.50 \%$ & 20 & $37.04 \%$ & 0.491 \\
\hline Mucin 2 & 4 & $11.11 \%$ & 6 & $25.00 \%$ & 0.162 \\
\hline Mucin 4 & 6 & $40.74 \%$ & 22 & $37.54 \%$ & 0.435 \\
\hline Cyclin D1 & 8 & $50.00 \%$ & 26 & $48.15 \%$ & 0.463 \\
\hline
\end{tabular}




\section{Discussion}

This review aims to introduce the main features of the some important molecular markers of biliary tract tumors.

My study include 70 patients who were suspicious of biliary tract malignancy, there is uneven age and gender distribution with maximum number of patients (36 of 70) between 50-60 years age group and female $(n=46,65.71 \%)$ to male $(n=24,34.29 \%)$ ratio of $2: 1$.

Among these 70 patient biopsy was positive for malignancy in $30(42.86 \%)$, these were designated as cases and those found negative were designated as controls 40/70(57.14\%).

Among cases all 30/30(100\%) were adenocarcinoma and as per tumour differentiation categorize as high grade18/30(60\%) and low grade12/30(40\%) (Well differentiated).

In our study when distribution of molecular markers was observed as per benign (controls) and malignant carcinoma (cases) it was found to have significant difference (P-value <0.05) for Muc-1 and Cyclin D1.

Among these markers Muc-1 expression are more specific whereas cyclin D1 expression is more sensitive indicator in differentiating between benign and malignant carcinomas.

Expression of Muc-2, Muc-4 was also higher in malignant cases than benign conditions mimicking carcinoma on radiological background but was statistically insignificant(P-value $>0.05)$.

In present study when distribution of molecular markers among cases (BTC) was observed it was found to be statistically significant $(\mathrm{P}$-value $<0.05)$ for Muc-1, Cyclin D1 thereby signifying their role in pathogenisis of BTC.

Expression of molecular markers among biliary tract malignancy (cases) in present study and their comparison with different studies:

\begin{tabular}{|l|l|c|l|}
\hline Markers & My study(cases) & Hyeon Kook Lee et al[2] & ShugoTamada et al[5] \\
\hline Muc-1 & $53.33 \%$ p-value 0.043 & $81.0 \%$ & $87.00 \%$ \\
\hline Muc-2 & $20.00 \%$ p-value 0.201 & $18.0 \%$ & Not included in their study. \\
\hline Muc-4 & $53.33 \%$ p-value 0.082 & $55.6 \%$ & $51.00 \%$ \\
\hline
\end{tabular}

\begin{tabular}{|l|l|l|l|}
\hline Marker & My study & Hong-Bing Ma et al[6] & Ai-Min Hui et al[7] \\
\hline CyclinD1 & $73.33 \%$ p-value 0.006 & $68.3 \%$-value $<0.05$ & $41 \%$ \\
\hline
\end{tabular}

* Expression of molecular markers as per grade of malignancy among different studies and present study:

\begin{tabular}{|c|c|c|c|c|c|c|c|}
\hline Marker & \multicolumn{3}{|c|}{ My Study (Histopathological Grade) } & \multicolumn{4}{|c|}{ Others Study (Histopathological Grade) } \\
\hline & High grade & Low grade & $\mathrm{p}$-value & \multirow{4}{*}{$\begin{array}{c}\text { Hyeon Kook Lee et } \\
\text { al[2] }\end{array}$} & High grade & $\begin{array}{l}\text { Low } \\
\text { grade }\end{array}$ & $\mathrm{p}$-value \\
\hline Muc-1 & $66.67 \%$ & $50 \%$ & 0.259 & & $84 \%$ & $76 \%$, & 0.517 \\
\hline Muc-2 & $11.11 \%$ & $33.33 \%$ & 0.146 & & $34 \%$, & $20 \%$, & 0.222 \\
\hline Muc-4 & $33.33 \%$ & $100 \%$ & 0.005 & & $63 \%$ & $44 \%$ & 0.134 \\
\hline $\begin{array}{l}\text { Cyclin } \\
\text { D1 }\end{array}$ & $66.67 \%$ & $100 \%$ & 0.057 & Ai-Min Hui et al[7] & $44 \%$ & $50 \%$ & $>0.05$ \\
\hline
\end{tabular}

In our study when expression of molecular markers was observed as per grade of malignancy,expression of Muc-4 significantly (p-value <0.05) correlates with high grade of malignancy.Expression of Muc1 is also more frequent in high grade malignancy, whereas expression of Muc-2, Cyclin D1 is usually associated with low grade malignancy but is statistically insignificant.

* Comparison of Prognostic significance of molecular marker among different studies and my study:

\begin{tabular}{|c|c|c|c|c|c|c|c|}
\hline \multirow{2}{*}{$\begin{array}{l}\text { Marker } \\
\mathrm{s}\end{array}$} & \multicolumn{3}{|c|}{ My study } & \multicolumn{4}{|c|}{ Others Study } \\
\hline & Survival & $\begin{array}{c}\text { Prognostic } \\
\text { significance }\end{array}$ & $\mathrm{p}$-value & & $\begin{array}{c}\text { Affect on } \\
\text { survival }\end{array}$ & $\begin{array}{l}\text { Prognostic } \\
\text { significance }\end{array}$ & $\mathrm{p}$-value \\
\hline Muc-1 & Decrease & Poor prognosis & 0.434 & \multirow{3}{*}{$\begin{array}{l}\text { Hyeon Kook } \\
\text { Lee et al[2] }\end{array}$} & Decrease & Poor & $>0.05$ \\
\hline Muc-2 & Better & Good Prognosis & 0.042 & & Better & Good & $>0.05$ \\
\hline Muc-4 & Decrease & Poor & 0. & & Decrease & Poor & 0.048 \\
\hline $\begin{array}{l}\text { Cyclin } \\
\text { D1 }\end{array}$ & Decrease & Poor prognosis & 0.844 & $\begin{array}{l}\text { Ai-Min Hui } \\
\text { et al[7] }\end{array}$ & Decrease & $\begin{array}{c}\text { Poor } \\
\text { prognosis }\end{array}$ & $<0.05$ \\
\hline
\end{tabular}

Also in present study Muc-2 expression is significantly associated with better survival then those without Muc-2 expression (P-value <0.042) and other molecular markers ( Muc-1, Muc-4,Cyclin D1) is 
associated with poor survival rates but these are not statistically significant (P-value >0.05). These finding indicates that expression of these markers are associated with poor prognosis though statistically insignificant, Hyeon Kook Lee et al (2012)[2] concluded that patients with MUC4 expression had significantly worse survival than those without MUC4 expression ( $\mathrm{P}=0.048)$, in a study on cyclin D1significance in BTC[155] Ai-Min Hui et al concluded that cyclin D1 over expression was significantly related to decreased overall survival $(P<0.05)$ in patients with GBC[7].

\section{Conclusion}

Cholangiocarcinoma is commonly considered a rare cancer. However, if we consider the hepato-biliary system a single entity, cancers of the gallbladder, intra-hepatic and extra-hepatic biliary tree altogether represent approximately $30 \%$ of the total with incidence rates close to that of hepatocellular carcinoma, which is the third most common cause of cancer-related death worldwide.The treatment is still quite unsuccessful and bile duct malignancies have overall poor prognosis. When untreated, bile duct malignancies lead to death usually within a few months [3][4].Biomarkers for screening programs and for follow-up of categories at risk are under investigation, however, currently none of the proposed markers has reached clinical application. For all these considerations, cancers of the biliary tree system should merit much more scientific attention also because a progressive increasein incidence and mortality for these cancers has been reported worldwideMuc-1 expression are more specific whereas cyclin D1 expression is more sensitive indicator in differentiating between benign and malignant biliary tract carcinomas in our study.

The expression of Muc-4 significantly correlates with grade of malignancy and is more frequent in high grade malignancy in our study.Among these molecular markers expression of Muc-2 significantly affect outcome and its expression is associated with better outcome in patients with Biliary tract malignancy in our study.

Given the smaller number of patients with BTC as compared with other common solid tumors, coordination of trials among institutions and cooperative groups, both nationally and internationally, and optimizing trial design, will be the key to future progress.

\section{References}

[1]. Alison MR, Poulsom R, Forbes SJ. Update on hepatic stem cells. Liver 2001; 21: 367-373

[2]. Lee et al.: Prognostic significance of muc4 expression in gallbladder carcinoma. World Journal of Surgical Oncology 2012 10:224

[3]. Wade, T.P.; Prasad, C.N.; Virgo, K.S., et al. Experience with distal bile duct cancers in U.S. Veterans Affairs hospitals. J SurgOncol1997; 64:242.

[4]. Fong, Y.; Blumgart, L.H.; Lin, E., et al. Outcome of treatment for distal bile duct cancer. Br J Surg1996;83(12):1712.

[5]. ShugoTamada, Hiroaki Shibahara, Michiyo Higashi, et al.MUC4 Is a Novel Prognostic Factor of Extrahepatic Bile Duct Carcinoma:Clin Cancer Res 2006;12:4257-4264.

[6]. Hong-Bing Ma, Hai-Tao Hu, Zheng-Li Di et al Association of cyclin D1, p16 and retinoblastoma protein expressions with prognosis and metastasis of gallbladder carcinoma :World J Gastroenterol2005;11(5):744-747

[7]. Ai-Min Hui, Xin Li, Ya-Zhou Shi, et al. Cyclin D1 Overexpression Is a Critical Event in Gallbladder Carcinogenesis and Independently Predicts Decreased Survival for Patients with Gallbladder Carcinoma Clin Cancer Res 2000;6:4272-4277 